Revista de Estudios Histórico-Jurídicos

[Sección Historia del Pensamiento Jurídico y Político]

XXXI (Valparaíso, Chile, 2009)

[pp. 427 - 445]

\title{
LA TEORÍA POLÍTICA DE SAMUEL PUFENDORF A TRAVÉS DE SU COMENTARIO A LA CONSTITUCIÓN DEL IMPERIO ROMANO-GERMÁNICO (1667)
}

["Political Theory of Samuel Pufendorf Through His Comments to the Constitution of the Holy Roman Empire (1667)"]

\author{
Marco A. Huesbe Llanos* \\ Pontificia Universidad Católica de Valparaíso \\ Universidad de Valparaíso
}

\begin{abstract}
RESUMEN
Este artículo surge de la necesidad de dar a conocer en español los contenidos del comentario a la Constitución del Imperio Romano-Germánico publicados en latín por Samuel Pufendorf en el año 1667. El artículo contiene las claves esenciales para comprender el pensamiento del autor alemán, que se caracteriza por su particular representación del Derecho natural y su efecto en la estructura jurídica del Estado moderno. Para la comprensión de la propuesta de Pufendorf se entrega un capítulo central que trata de los diversos escritos de nuestro autor. Finalmente, este artículo en la primera parte presenta una amplia información sobre la fuente misma y da cuenta de nuestra traducción al español.

Palabras clave: Pufendorf - De statu imperii-Derecho Natural.
\end{abstract}

\begin{abstract}
This article results from the need to convey, in Spanish, the contents of the comments to the Constitution of the Holy Roman Empire that Samuel Pufendorf published in Latin in 1667. The article contains the basic keys to understand the thinking of the German author, characterized by his peculiar representation of natural Law and its effect in the juridical structure of the Modern State. In order to understand Pufendorf's proposal, a central chapter that deals with the different writings of our author is put forward. Finally, in the first part of this article, we present broad information regarding the source and we give an account for our translation into Spanish.

Keywords: Pufendorf - De statu imperii-Natural Law.
\end{abstract}

* Profesor titular de Historia Institucional de la Escuela de Derecho de la Universidad de Valparaíso y Profesor de Historia del Pensamiento Político de la Pontificia Universidad Católica de Valparaíso. Dirección postal: Avenida Brasil 2950, Valparaíso, Chile. Correo electrónico: mahuesbe@yahoo.es Esta investigación ha sido posible gracias al apoyo del proyecto FONDECYT No 1070318. 


\section{LOS TEXTOS CONSTITUCIONALES DE SAMUEL PUFENDORF: LOS CAMBIOS DE SISTEMAS POLÍTICOS EN EL SIGLO XVII Y EL ANÁLISIS DE LA CONSTITUCIÓN DEL IMPERIO}

Es muy sabido que las grandes transformaciones del sistema político europeo tuvieron lugar a fines del siglo XVIII, mediante la Revolución de las colonias americanas de Inglaterra (1776) y la Revolución francesa (1789). A estos acontecimientos también se agregan el Act of Toleration y el Bill of Rights, ambos de 1688-1689. Sin embargo, es necesario señalar que estas transformaciones tuvieron una larga gestación durante el siglo XVII, lo cual se aprecia en dos importantes textos políticos, que dan cuenta de tales cambios, por lo menos en el contenido lingüístico de cada uno de ellos, que introducen importantes innovaciones en la comprensión del fenómeno político-constitucional de su tiempo. Se trata, por un lado, de la Lex regia Danica, emitida el 14 de agosto de $1665^{1}$ bajo la monarquía de Federico III y redactada por Peter Schumacher-Grieffenfeld, canciller del Reino, que entonces comprendía Jutlandia, Noruega, Scania, Islas Far- Oe y Groelandia; y, por otro, del De statu imperii germanici, publicado en 1667 por Samuel Pufendorf (1632-1694), bajo el seudónimo de Severinus de Monzambano².

Estos textos invitan a una comparación. Uno es confesional, según "la pura e

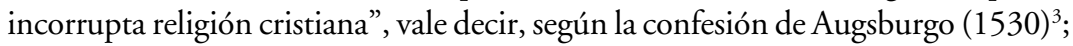
y el otro asegura la fe luterana, que forma parte de la tradición igual que las demás confesiones cristianas existentes en el imperio; uno es absolutista y el otro es republicano ${ }^{4}$. Uno se emitió, pero no se publicó; y el otro texto se publicó pero no declara quién es su autor real. Uno es brevísimo y el otro es extenso. Ambos

${ }^{1}$ Lex Regia de jure supremae potestatis et haereditariae successionis Regni Danae, en Lex regia Frederici Tertii ad mandatum Sae. Regiae majestatis propium (Kopenhavn, 1655). Hay traducción parcial al castellano como "Apéndice III" a Huesbe, Marco Antonio, Una constitución de la época del absolutismo: la "Lex regia Danica" de 1665, en Revista de Estudios Histórico-Jurídicos 1 (Valparaíso 1976), pp. 115-117.

${ }^{2}$ Severinus de Monzambano Veronensis [= Pufendorf, Samuel], De statu imperii Germanici ad Laelium fratrem, dominum Trezolani, liber unus (Genevae, apud Petrum Columesium, 1667). Véase nuestra traducción: Pufendorf, Samuel, La Constitución del Imperio alemán. 1667 (Valparaíso, Edeval, 2009) (que citaremos como Constitución). Para la vida de Pufendorf, véase: Denzer, Horst, en Samuel Pufendorf, Die Verfassung des deutschen Reiches. Übersetzung, Anmerkungen und Nachwort (Stuttgart, Philipp Reclam, 1985), pp. 161-220. También: SeIDler, Michael, The Works of Samuel Pufendorf, escrito introductorio a PufenDORF, Samuel, The Present State of Germany (traducción de Edmund Bohun, Indianapolis, Liberty Fund, 2007), pp. ix-xx.

${ }^{3}$ Véase: Huesbe, Marco Antonio, Die konstitutionelle Auseinandersetzung "Absolutismus vs. Liberalismus" in der deutschen Politikwissenschaft des 17. Jahrhunderts: Johannes Althusius vs. Henning Arnisaeus, en Jurisprudenz, Politisce Theorie und Politische Theologie. Beiträge des Herborner Symposions zum 400. Jahrestag der Politica des Johannes Althusius 1603-2003 (Berlin, Duncker u. Humblot, 2004), pp. 438-450.

${ }^{4}$ En esta parte de la constitución danesa se enumeran los artículos propiamente constitucionales de este documento los que están expuestos en siete párrafos de la Lex Regia. En la articulación de esta lex encontramos la raíz de lo que se entiende en la publicística del $S$. XVII por los inicios del republicanismo. Véase: Huesbe, Marco Antonio, Una constitución de la época del absolutismo (n. 1), pp. 115-117. 
tratan de los atributos del poder soberano mediante los cuales se determina el grado de participación política en el gobierno del Estado y, además, fijan la forma del Estado por medio de los actores respectivos.

Si bien en los dos textos existe una razón suprema reguladora y siguen un orden lógico común, concerniente a un orden jerárquico superior, cabe señalar las diferencias. Uno empieza con Dios y el otro con un seudónimo de un renacentista ilustrado republicano: Monzambano, quien tiene la particularidad de presentarse como un observador neutral de los acontecimientos históricos de ese tiempo tan acotado.

Sobre lo que no cabe duda es que ambas lecturas son expresión múltiple del mundo barroco, monárquico-republicano, burgués e ilustrado de su tiempo; aun cuando el primero fue aprobado por el Parlamento conjuntamente con el rey Federico III de Dinamarca, hijo del legendario Christian IV; y, en cambio, el segundo es solo una creación del autor, pero, su base descansa en la realidad del Imperio.

Debemos advertir que ambos textos políticos son los pasos iniciales del gran cambio que se aproxima y culmina con la Gloriosa Revolución de 1689 en Inglaterra (The Bill of Rights, 13 de febrero de 1689), que es el más liberal de los tres textos constitucionales que llevamos mencionados ${ }^{5}$.

En efecto, la constitución regia danesa de 1665 consagra el absolutismo moderno en tanto que establece la monarquía hereditaria, la centralización del poder y la determinación de los derechos de la majestad de acuerdo con la coherente y muy fundada propuesta del jurista alemán Henning Arnisaeus ${ }^{6}$. Por su parte, Samuel Pufendorf, inspirado en la propuesta del círculo arniseano (Conring, Grocio, Hobbes), en su tratado sobre la Constitución del imperio alemán ${ }^{7}$ describe en el siguiente y mismo orden, los derechos del soberano y su significado en el Derecho público imperial concreto: i) derecho de dictar leyes; ii) derecho de nombrar magistrados; iii) derecho de fijar impuestos y cobrar tributos; iv) derecho de declarar la guerra y concertar la paz; v) derecho sobre los asuntos religiosos; vi) derecho

\footnotetext{
${ }^{5}$ Para el texto completo en español del Bill of Rights (Declaración de Derechos de 1688) Véase: Sutherland, Arthur, De la Carta Magna a la Constitución Norteamericana. Ideas fundamentales sobre Constitucionalismo (Buenos Aires, TEA, 1972), pp. 117-126. Para una excelente introducción al pensamiento político del siglo XVII, véase: ALLEN, John William, A History of Political Thought in the Sixteenth Century (London, Methuen, 1960). Un estudio sobre el sentido de la revolución inglesa y el republicanismo, cf. STONE, Lawrence, La revolución inglesa, en ELLIOT, Jack Hale y otros (editores), Revoluciones y rebeliones de la Europa Moderna (Madrid, Alianza Editorial, 1986), pp. 120-121. De acuerdo con Robert Foster y Jack P. Greene no se debiera incluir entre los movimientos revolucionarios las revueltas siciliana y napolitana de 1647-1648, porque consideran este movimiento "jacqueries" urbanas o estallidos populares provocados por el descontento social y dirigidos no contra el gobierno sino contra el grupo social que ostentaba el gobierno local. Lo mismo respecto de la sublevación catalana y la portuguesa de ese período que carecía de un pensamiento unificador y de una dirección organizada necesaria para emprender con éxito una transformación efectiva en el país. Véase: Elliot, J. H, cit. ibi, p. 16.

${ }^{6}$ Arnisaeus, De jure majestatis (1610), 1,1-5; El mismo, De Republica (615), 1.

${ }^{7}$ Véase: PufEndorf, S., La constitución, cit. (n. 2), 4,5-9.
} 
sobre los bienes fiscales (ius in bona fiscalia); y vii) derecho de acuñar moneda ${ }^{8}$. Téngase presente que estos son los mismos derechos atribuidos por T. Hobbes al poder soberano por institución con independencia de la forma de gobierno que se postule, en el muy citado capítulo 18 del Leviathan 9 . Así es como, paso a paso, se configuran las instituciones del Estado westfaliano y permanecen inalterablemente vigentes hasta promediar 1848, con excepción de Inglaterra y las colonias del Este de América que desarrollan los derechos individuales de las personas.

El escrito de Pufendorf sobre la constitución imperial es una de las pocas obras de este género, que, en su tiempo, fue más allá de los estudios anteriores realizados sobre este tema. Hasta el día de hoy atrae el interés de un gran público ya que es leída con mucha curiosidad, deleite e interés político. Seguramente, un fundamento para tal éxito se deba a la novedad revolucionaria que el ensayo de Pufendorf ofrece, por sobre todas las demás representaciones del orden estatal de su tiempo.

En esta oportunidad, conviene destacar tanto la claridad de juicio que Pufendorf ofrece sobre el Derecho constitucional imperial, como también el análisis objetivo de la realidad constitucional, que emergen de este escrito sobre el Imperio, una vez terminada la Guerra de los Treinta Años (1618-1648). Su visión se impone gracias a la percepción conjunta de decisiones jurídicas, consideraciones políticas y fundamentos históricos. Todo esto solo no basta para la explicación de la inquebrantable vitalidad del escrito. A la relevancia intrínseca de su contenido debe también añadirse el brillo del lenguaje. En efecto, Pufendorf extrae todos los valores del lenguaje, desde la galantería, ironía y el humor de trasfondo hasta la sátira, el sarcasmo punzante por causa del firme propósito de exaltar mejor la realidad. Además de la precisión conceptual del texto resalta, en contraste, la prolijidad de la erudición con que expone los diversos temas concernientes a distintos períodos de la historia institucional del Imperio ${ }^{10}$.

Antes de concluir este capítulo, es menester dar noticia de una cuidada edición inglesa, que es la última del libro de Pufendorf, debida a Michael J. Seidler $(2007)^{11}$. Él coloca a Pufendorf nuevamente en la discusión constitucional de nuestro tiempo, esta vez, referida a la estructura política de la propuesta de la Unión Europea. La edición está provista de una sensibilidad especial, reflejada en una expresión política favorable a la forma de gobierno monárquica, siguiendo a Bohun, en la que se intercala diversa información proveniente de la mirada a una misma fuente (Pufendorf), sin poderse precisar con toda certeza cuál es el texto original latino de donde surge este nuevo texto en inglés. En todo caso, sabemos que existen diecinueve ediciones latinas, cuatro ediciones en alemán, tres francesas

\footnotetext{
${ }^{8}$ Véase: S. Pufendorf, S., La constitución, cit. (n. 2), 5,5-9.

${ }^{9}$ Hobbes, Thomas, Leviathan or the Matter, Form and Power of a Commonwealth Eclesiastical and Civil (Amsterdam, 1668), 2, 18.

${ }^{10}$ Véase: la controversia que inicia Pufendorf con Hippolytus a Lapide (1605-78) en torno a la oscuridad de la estructura del Imperio y el ordenamiento del Estado. Véase: PUfENDORF, La constitución, cit. (n. 2), 6, 7.

${ }^{11}$ Seidler, Michael, "Introduction" a Pufendorf, Samuel, The Present State of Germany (trad. Edmund Bohun, Indianapolis, Liberty Fund, 2007).
} 
y dos inglesas. Para nuestro propósito, es importante colocar un hito en el año 1922, cuando fue realizada la edición de Harry Bresslau ${ }^{12}$, puesto que será uno de los textos básicos para nuestra traducción. Anteriormente hubo dos traducciones al alemán moderno, a saber la primera de Bresslau ${ }^{13}$ y la traducción de Heinrich Dove, en Leipzig, se supone que es de 1880.

Finalmente, existen las dos traducciones de Horst Denzer, bajo el título Die Verfassung des deutschen Reiches ${ }^{14}$, y la edición paralela: Die Verfassung des deutschen Reiches de Samuel von Pufendorf de 1994'15. También es importante la reedición realizada por Notker Hammerstein, de una temprana traducción al alemán bajo el título Monzambano, eines veronesers ungeheurter offenherziger Discurs, oder Gründlicher Bericht von der wahren Beschafenheit und Zustand des Teuschen Reichs ${ }^{16}$. Para nuestra investigación, de las traducciones de las ediciones antiguas, solamente es importante la primera edición de 1667 y la llamada editio posthuma, publicada en 1706, en la que Pufendorf renuncia a su seudónimo (Monzambano) y varía levemente el texto en su contenido. En realidad estas últimas son las únicas ediciones que el mismo Pufendorf dio para la imprenta y por eso, a nuestro parecer, ofrecen un texto auténtico. Ambas compilaciones cuentan con un análisis crítico y fueron contrapuestas por Fritz Salomon (Weimar, 1910). Las ediciones de Salomon se encuentran en diversas bibliotecas de Europa Central y son de fácil acceso. Las traducciones modernas al alemán de Bresslau, se basan en la primera edición. La realizada por Dove, en cambio, se basa en la editio posthuma. Para nuestra traducción al español no dispusimos de ningún texto anterior en dicho idioma. Nosotros seguimos la traducción de H. Breslau y la confrontamos con la edición de H. Denzer, ya que ésta proporciona indicaciones importantes respecto de algunas variaciones del latín original, que señalamos oportunamente. Igualmente hemos revisado las notas de Denzer para la publicación de esta traducción y así asegurar un correcto uso de los términos en nuestra traducción española que resulta ser la primera traducción al español.

\section{EL ANÁLISIS CONSTITUCIONAL DE PUFENDORF}

La edición latina del escrito de Samuel Pufendorf: De statu imperii germanici hodie, de 1667, bajo el seudónimo italianizante de Severinus Monzambano, refleja, sin duda, las dificultades que en ese tiempo podían precipitarse sobre los

${ }^{12}$ Monzambano, Severinus von, Über die Verfassung des deutschen Reiches (traducción e introducción por Harry Bresslau, Berlín, 1922).

${ }^{13}$ En Historisch-politischen Bibliothek (Berlín, 1870), 7 vol.

${ }^{14}$ Pufendorf, Samuel, Die Verfassung des deutschen Reiches (Stuttgart, Philipp Reclam Jun, 1985).

${ }^{15}$ Pufendorf, Samuel Die Verfassung des deutschen Reiches (traducción de Horst Denzer, Stuttgart, 1994)

${ }^{16}$ Samuel PUfENDORF, Monzambano, eines veronesers ungeheurter offenherziger Discurs, oder Gründlicher Bericht von der wahren Beschafenheit und Zustand des Teuschen Reichs, geschrieben an seinen Bruder Laelium von Monzambano. Herren zu Trezoland [...] ins teutsche übersezet durch ein ungenantes Glied der hochlöblichen Fruchtbringeden Gessellschaft. 1669 [reimpreso en Staatslehre der frühen Neuezeit (Frankfurt am Main: Deutscher Klassiker Verlag, 1995)]. 
autores, debido a la permanente censura imperante hacia los escritos, tanto en el mundo protestante como en el medio católico, que, por supuesto, también podía ser autocensura, como parece ser el caso de Pufendorf. En realidad, en ese mismo año debe salir de la vieja Universidad de Heidelberg, ya que la hostilidad de los catedráticos tradicionalistas contra Pufendorf era manifiesta ${ }^{17}$. Éste se dirigió a Lund (Suecia) donde contaba con algunos amigos que lo requerían y con el apoyo de Carlos XI de Suecia y su hermano Esaias, se traslada a la Universidad de Lund. En ese espacio de tiempo escribe su primer tratado de Derecho público, que nos sirve para captar en forma más prístina su pensamiento. Pufendorf indica en su introducción que él no solo escribe para el conocimiento acertado de las instituciones del Imperio, sino también para que de allí se pueda fijar una estructura y un contenido claro de lo que se consideró una presunta especie de monstruosidad constitucional; carácter que muchos eruditos le atribuían a la estructura políticosocial del Imperio (Pufendorf, Constitución 6,9).

En efecto, Pufendorf señala que para entender el significado de la estructura constitucional del Imperio es preciso conocer su historia y para eso dedica un extenso primer capítulo, compuesto de quince subtítulos, a narrar la historia del Imperio alemán, que en algunos momentos parece la representación patriótica de la cultura política alemana. Precisamente, en este apartado del escrito, se propone dominar racionalmente el espacio geográfico y sus límites (las fronteras de la antigua Germania); también, expone el transcurso histórico de su tiempo político (la constitución del viejo Imperio) y su origen y pertenencia cultural.

Dicho todo lo anterior, debe considerarse que los debates de Pufendorf sobre Derecho e historia de la constitución imperial alemana, deben ser considerados desde dos puntos de vista.

En primer lugar, las explicaciones sobre el Derecho constitucional sirven al autor para la ejemplificación de las aseveraciones generales de su doctrina sobre el Derecho natural dentro del orden concreto de la vida en comunidad, materia que trata Pufendorf en ocho capítulos y los distribuye como sigue: i) los Inicios del imperio alemán; ii) la división de los estamentos; iii) el surgimiento de los estamentos del Imperio; iv) el emperador como cabeza del Imperio alemán, su elección y los príncipes electores; v) los límites del poder imperial mediante las capitulaciones, leyes y costumbres reguladas por medio de los estamentos; vi) las formas estatales y el Imperio alemán; vii) fuerza y debilidad del imperio alemán; y viii) la razón de la constitución y el Imperio alemán.

En segundo lugar, en esta obra, el fin general del Derecho natural será especificado por sobre el Derecho estatal, eso sí, a partir de la utilidad que éste tenga para el Estado concreto. Su propuesta sobre el Derecho natural se sitúa en la misma línea de Arnisaeus, Grocio, Selden y Hobbes, conocida como racionalismo iusnaturalista o modernidad jurídica. El propósito de exponer las bases filosóficas de la doctrina iusnaturalista es evidente para limpiar las ciencias de vicios aristotélico y escolásticos y liberar de supuestos finalistas al Derecho natural. A su vez,

${ }^{17}$ Véase: Huesbe, Marco Antonio, La constitución de Pufendorf, en Homenaje al Profesor P. L. Weinacht (Santiago 2009). 
la irregularidad de la constitución imperial, dentro del contexto de la teoría de la soberanía pufendorfeana, descansa en la doctrina de las formas estatales, tal como él mismo lo propone en sus disertaciones: De republica irregulari y De systematibus civitatum y en el tratado sobre la Constitución del Imperio (hodie), donde concluye que esta arquitectura imperial no se homologa con ninguna forma regular de Estado, y que el imperio es una forma irregular de Estado, pero no un monstruo (Pufendorf, Constitución, cap. 6,9), como se lo suele calificar. Es por esta razón que Pufendorf, en sus obras políticas, nunca pierde el punto de referencia de la Constitución imperial, con su novedosa doctrina de la política y con su visión y representación positiva del Derecho natural, que, sin duda, ambas forman el centro de la obra de Pufendorf y establece criterios de conducta que regulan la vida de los ciudadanos mediante concretas disposiciones morales.

Por último, en cuanto a la mayor proximidad al texto original, podemos concluir que, con el fin de conservar el estilo y el contenido prístino del primer escrito de Pufendorf, la traducción al alemán de H. Bresslau, de 1922, es la que proporciona, en gran parte, la pureza de la primera edición. Los motivos decisivos para esta opción son presentados por el historiador alemán H. Denzer: "La frescura y la inmediatez del primer lanzamiento, el juicio sin maquillar, lo colorido del lenguaje se han perdido en la editio potshuma" ${ }^{18}$. En efecto, en la última edición que conocemos, Pufendorf juzgó más circunspectamente, suavizó muchos ataques que eran ácidos, corrigió algunos errores y consideró la evolución histórica del Imperio a partir de la primera edición. Así, cuando finalmente Samuel Pufendorf publicó su escrito sobre la Constitución imperial en 1667, lo hizo bajo el ya referido seudónimo de un prestigioso y ficticio estudioso italiano, Severinus de Monzambano, de Verona, manteniendo la forma del escrito en todo aspecto, el cual dirigió a su hermano Laelius, con el fin de darle mayor credibilidad a todo el documento.

\section{ESTUDIOS, FORMACIÓN Y ESCRITOS DE PUFENDORF. SU TEORÍA DEL DERECHO NATURAL}

\section{Formación académica}

Samuel Pufendorf (1632-1694) provenía de Sajonia y, como muchos otros juristas de la época, era hijo de un riguroso y muy docto pastor luterano E. J. Pufendorf, que influyó notablemente en su formación inicial y en sus creencias religiosas. Fueron los tiempos cuando Federico III de Dinamarca (1648-1670) emitió su constitución de 1665, propuesta por su canciller Peter Schumacher con la aprobación del Parlamento ("Richatag"), luego de la revolución burguesa de nobles y comerciantes de Copenhague en 1662. Además, fue un período importante para la historia espiritual europea, puesto que en 1632 nacieron J. Locke, padre del liberalismo y de la tolerancia política y Galileo el fundador de la doctrina científica ${ }^{19}$.

\footnotetext{
${ }^{18}$ Véase: Denzer, Pufendorf, cit. (n. 2), p. 209.

${ }^{19}$ Véase el aún muy sugerente y completo tratado sobre la comprensión filosófica del mundo en el siglo XVI: DiltheY, Wilhelm, Hombre y mundo en los siglos XVI y XVII (trad. cast.,
} 
Aun cuando Pufendorf nació en un mundo rural en la Alemania sajona, se puede sostener que su formación fue la de un hombre humanista y muy abierto para la interpretación de su medio y gran observador de su realidad histórica concreta. En efecto, desde 1645 a 1650 frecuentó una escuela tradicional luterana en Grimma ${ }^{20}$. Como hijo de un párroco luterano, aprendió Gramática, Retórica y Lógica en la escuela, hizo detenidas lecturas bíblicas y se inició en la dogmática de Lutero ${ }^{21}$. En esa oportunidad adquirió el dominio del latín con la lectura de los escritos teológicos de los reformadores y además adquirió un exhaustivo conocimiento de las obras clásicas de la Antigüedad. En el semestre invernal de 1650 asistió a la Universidad de Leipzig, para estudiar Teología. Sin embargo, abandonaría luego esos estudios porque para un espíritu humanista era éste un territorio demasiado tradicionalista e inseguro. No obstante, emprendió la defensa de la enseñanza de la Teología protestante a través de la escuela filosófica aristotélica, al modo como se enseñaba en la reconocida Universidad y Academia de Helmstedt ${ }^{22}$. Pufendorf cuenta en la carta dedicatoria al texto sobre la Constitución del Imperio que, después de un viaje a Berlín, visitó la corte del duque de Braunschweig, donde entró en contacto con un importante profesor, Hermann Conring (1606-1681), de la Universidad de Helmstedt (1576). La Academia de Helmstedt había sido fundada por el príncipe con el propósito de evitar que los jóvenes estudiantes fueran contaminados con las doctrinas de los seguidores de Lutero y de otros territorios que habían aceptado la "formula concordiae" (1576), que, como lo indica su texto, buscaba encontrar los medios teológicos que pudieran preparar la unidad del protestantismo alejándose del auténtico Lutero. Debido al fuerte rechazo a la formula por parte de la Universidad de Helmstedt, ésta adquiriría un carácter más liberal, por lo cual se la conocía, y se convertiría en el centro de estudios más requerido del luteranismo nórdico de la primera mitad del siglo XVII.

Por último, la Academia Julia (nombre debido al Duque Julius) se fundó también con el propósito de preparar a los futuros abogados y administradores

México, 1947), pp. 101-254. Para una cabal comprensión de los “malabares” de las ediciones de libros en los siglos de la ilustración véase DARNTON, Robert, El negocio de la Ilustración. Historia editorial de la Encyclopédie, $1775-1800$ (trad. F.C.E., México 2006), pp. 105-146.

${ }^{20}$ Para los programas de enseñanza en las escuelas alemanas reformadas, véase también nuestra traducción del escrito de M. Lutero, donde expone su propuesta de reforma de la enseñanza en Alemania, en Huesbe, Marco Antonio - Carvajal, Martín Lutero y Juan Calvino. Fundamentos del Mundo Moderno (Valparaíso, Ediciones Universitarias de Valparaíso, 2003), pp. 253-285; Véase también: Robert Darnton, El negocio, cit. (n. 19), pp 1-40.

${ }^{21}$ Véase: Para una biografía completa sobre Pufendorf léase a Döring, Detlef, PufendorfStudien: Beiträge zur Biographie Samuel Pufendorf und seine Entwicklung als historischer und theologisher Schriftsteller (Berlin, Dunker und Humblot, 1992).

${ }^{22}$ No debemos olvidar que H. Arnisaeus publicó tres tratados dedicados al estudio del derecho público y cuentan con varias ediciones. Véase: Arnisaeus, Henning, Opera Omnia editada sucesivamente en 1630 y luego en 1648 en las cuales incluye Doctrina politica 1606, de Jure majestatis 1610 y De republica 1615 debido a una fuerte controversia con ALTHUSIUS, Johannes, Politica methodice digesta (Herborn, 1603). Véase: Huesbe, Marco Antonio, Die konstitutionelle Auseinandersetzung, cit. (n. 3), p 437-461. 
de las posesiones de estos territorios ${ }^{23}$. Allí enseñaban el humanista y profesor de Metafísica Cornilius Martini, el teólogo ecumenista Georg Calixtus, el jurista y publicista Henning Arnisaeus, el humanista y destacado civilista Hermann Conring, con quien se encontró Pufendorf en su viaje imaginario por Alemania ${ }^{24}$.

En vez de inclinarse a la Teología, Pufendorf inició sus estudios de Derecho público, de Filosofía natural, e incluso de Medicina, tal como ocurrió con sus antecesores Arnisaeus y Conring ${ }^{25}$. Más tarde pasó a Jena, otra de las grandes universidades luteranas junto a Helmstedt, Wittenberg, Halle y Frankfurt en el $\mathrm{Oder}^{26}$. En Jena inicia sus estudios de Ética y Política. En efecto, Pufendorf encontró en el estudio del Derecho natural el fundamento que se constituiría en el principio básico para ordenar el conocimiento del mundo social en el Imperio ${ }^{27}$. En esa universidad supo de la filosofa matemática enseñada por el académico Erhard Weigel, matemático y filósofo (1625-1799), amigo de R. Descartes (1596-1650), que influyó sobre Th. Hobbes (1588-1679), entre muchos.

Weigel llevó el método matemático-demostrativo a la Filosofía moral. Aspiraba a regular las relaciones entre los hombres, las cosas, las personas, las comunidades y sus condiciones y particularidades según principios matemáticos y llevarlas a un sistema correspondiente a números (R. Descartes). Distinguía las cosas naturales de las morales, las cuales se diferencian con cifras y valores numéricos. Con esto intentaba diferenciar la naturaleza de las cosas, a pesar de la cuantificación de las relaciones entre el mundo físico puro y el mundo de las relaciones morales humanas; en esto también siguió Pufendorf a Weigel. Por sugerencia de éste, aquél se ocupó con Descartes, Galileo, Grocio y Hobbes ${ }^{28}$. En la primavera de 1658 recibió el título de magíster, como lo dice Pufendorf "para buscar fama y patronazgo" 29 . No es muy extraño que haya obviado el grado doctoral por no

${ }^{23}$ Véase: Huesbe, Marco Antonio, Untersuchungen, zum Einfluss der Schule von Salamanca auf das luttherische Staatsdenken im 17 Jahrhundert (Diss. Mainz 1965), pp. 1-25

${ }^{24}$ Para un estudio comparado de estos autores y sus respectivas propuestas véase la reciente publicación de Gelderen, Martin Van, The State and its Rivals in Early-Modern Europe, en Skinner, Q. (editor), State and Citizens: History, Theory, Prospects (Cambridge, 2003), p. 91.

${ }^{25}$ Hermann Conring, discípulo de H. Arnisaeus (1575-1636) en la Universidad de Helmstedt, fue un destacado jurista e iniciador de la moderna codificación del derecho civil alemán, es mencionado por Pufendorf en varias ocasiones debido a la excepcional estimación que goza, en el mundo europeo, por su erudición jurídica y humanista. También mantuvo con él correspondencia epistolar. Véase: Pufendorf, S., Die Verfassung, cit. (n. 2), pp. 8-9; Para datos biográficos de H. Arnisaeus. Véase: Huesbe, Marco Antonio, Teoría, Administración y participación en el Estado moderno. Bodino, Arnisaeus, Beza (Valparaíso, Ediciones Universitarias de Valparaíso, 2008), pp. 101-12. Para H. Conring Véase: Willoweit, Dietmar, Hermann Conring, en STOLleIS, Michael (editor), Staatsdenker im 17. Jahrhundert. Reichspublizistik, Politik, Naturrecht (Frankfurt am Main, Metzner, 1987), p 129-147.

${ }^{26}$ Véase: M. STOLLEIS, Geschichte des öffentlichen Recht (München, 1988), pp. 233-238.

${ }^{27}$ Ibíd., pp. 282-284.

${ }^{28}$ Para Weigel véase: Dorschner, Johann, Erhard Weigel und seine Zeit, en Schielicke, Reinhard y otros (editores), Erhard Weigel 1625 bis 1699. Barocker Ersvater der deutschen Früaufklärung. Beiträge des Kolloquiums anlässlich seines 300. Todestages am 20. 1999 in Jena (Jena, 1999), p. 1139.

${ }^{29}$ Ibíd. 
querer caer en manos de los teólogos tradicionalistas y asumir su método escolástico; pero perseveró en obtener el grado de magíster porque era necesario para una carrera académica.

\section{El Derecho natural social en Pufendorf.}

Por medio de una intervención de su hermano Esaias, quien se encontraba en una misión diplomática en Suecia, se dirigió Pufendorf a Copenhague, al igual que otros grandes juristas de ese siglo. El luteranismo liberal se había desplazado de Helmstedt hacia a los países escandinavos (Arhus, Copenhague, Lund). En efecto, Pufendorf consiguió un puesto de tutor en casa del enviado sueco Coyet en Copenhague ${ }^{30}$. Apenas había llegado cuando estalló la guerra entre Dinamarca y Suecia, y fue hecho prisionero por ocho meses. Durante este tiempo y bajo la influencia de Weigel, escribió su primera obra iusnaturalista: Elementorum jurisprudentiae universalis libri duo, la cual hizo imprimir en 1660 en La Haya, en la Holanda libre ${ }^{31}$. Con esto Pufendorf intentó derivar la construcción conceptual de su Derecho natural al terreno puramente deductivo. Consecuente con el actuar moral a través del libre albedrío de los hombres, en esta obra, procede a fundamentar el sistema teórico. De acuerdo con su percepción del Derecho natural, propone distinguir para el análisis de la realidad según su objeto, sus principios, naturaleza y efecto. De este modo llega a formular el más importante edificio conceptual del Derecho natural con conceptos tales como persona, título, poder, derecho, honor, precio, obligación, ley, cantidad, calidad, afrenta. Sin embargo, si bien alcanza una construcción conceptual definitoria, destruye las referencias objetivas que debieron pertenecer a la doctrina iusnaturalista tradicional. Es por eso que, en el segundo libro, después del capítulo que trata de los axiomas, siguen las observaciones sobre la naturaleza de los hombres y el Derecho natural, los que no están en relación con su anterior construcción conceptual.

En esta nueva postura, formula la más importante contribución a la interpretación del Derecho natural. Pufendorf cree que los individuos solamente a partir de la experiencia llegan a afirmaciones verdaderas sobre la naturaleza de la razón, el libre albedrío y la tendencia social de los hombres. Además, sostiene que sólo la razón depara a éstos una vida armoniosa en comunidad y sólo el poder humano de mandar puede asegurar la vida social. Estas propuestas conducen a Pufendorf hacia una edificación plenamente histórico racional que da origen a la constitución del Imperio germano.

\section{La red de influencia jurídico-constitucional de Pufendorf.}

Después de liberarse de compromisos de trabajo anteriores, Pufendorf viajó

\footnotetext{
${ }^{30}$ Véase: Huesbe, Marco Antonio, Die Rezeption des Staatslehre des Henning Arnisaeus in Europa und Dänemak, en Goll, Th. Y otros (editores), Staat und Politik. Beiträge aus Politischer Wissenschaft und Politischer Bildung. Festschrift für Paul-Ludwig Weinacht zum 65. Geburtstag (Baden- Baden, Nomos, 2003), pp.110-119. Para la estadía de H. Grocio en Suecia en la Corte de la reina Cristina, véase Tuck, Richard, "Introduction” a Grotius, Hugo, The Right of War and Peace (trad. de Richard Tuck, Indianapolis, Liberty Fund, 2005), pp. 61-62.

${ }^{31}$ Citado en la edición de Frankfurt - Jena, 1680.
} 
a Holanda y se inscribió en la Universidad de Leiden. Ahí conoció a Pieter de Groot, el hijo de Hugo Grocio, quien dirigía la política exterior del príncipe elector Carlos Ludovico del Palatinado, especialmente para la coordinación de los asuntos confesionales en esa esquina crítica de Europa. Consiguió esta oportunidad debido a la importante participación que obtuvieron los seguidores de Calvino en los principados alemanes del noroeste, lo cual, a su vez, daba origen a la necesidad de tener un encargado especial con dominio certero de la Filosofía y la Teología, para concertar las diversas disputas teológicas y las conveniencias políticas con las diversas confesiones calvinistas dominantes en Holanda y norte de Alemania. La recomendación de Grocio ante el príncipe, su primer escrito iusnaturalista y sus buenas referencias sirvieron para que el elector primero le ofreciera un puesto como profesor de Derecho romano, que Pufendorf rechazó, "porque -como cita Horst Denzer el estudioso de Pufendorf- no tenía deseos de agregar el comentario número 1000 a los 999 otros comentarios sobre las instituciones"32.

El interés de Pufendorf por un puesto como profesor de política en la facultad de Derecho tropezó con la resistencia de grupos adversarios en la universidad. Por esto, el elector lo destinó en la recién creada cátedra extraordinaria de Derecho de Gentes y de Humanidades en la Facultad de Filosofía, en la cual, gracias a su empeño, pronto se convirtió en un profesor titular para enseñar Derecho Natural y de Gentes, primera cátedra de este tipo en Alemania. Aquí Pufendorf pudo desarrollar su doctrina iusnaturalista gracias a su largo currículo como catedrático ${ }^{33}$.

Por otra parte, Pufendorf también se ocupó de cuestiones constitucionales, puesto que buscaba hacerse de una cátedra de derecho constitucional alemán en la Facultad de Derecho. Pufendorf sospechaba, con razón, que esta dotación le significaría un reconocimiento académico mayor. Esto lo demuestran sus primeras disertaciones en la facultad "pro disputationibus": De obligatione erga patriam y su escrito sobre la constitución del Imperio alemán de 1667.

Debido a disputas con sus colegas juristas, fracasó la solicitud para la vacante de profesor de Derecho constitucional en 1664 y los ataques de Pufendorf hacia el gremio de juristas en el escrito sobre la constitución del Imperio empeoraron el clima en la universidad, por lo que Pufendorf, en 1667, aceptó la propuesta del rey sueco Carlos XI para asumir una cátedra en la recién fundada Universidad de Lund (1658) y saltar, de ese modo, al otro lado del estrecho, hacia la península escandinava. Antes de viajar a Lund, escribió, presumiblemente en Heildelberg, su análisis de la constitución del Imperio, que fue publicada en esa misma ciudad el año 1667, bajo el seudónimo de Monzambano, como hemos recordado, con el propósito de aquietar las aguas entre los defensores del arraigado centralismo absolutista y los partidarios de la acumulación de derechos en manos de los estamentos y sus privilegios. Este escrito, además de su significado como fuente del Derecho constitucional, vale por la mágica descripción sintetizada de la historia de la Germania hasta 1667, que puede ser considerada como la última saga medieval de este genero.

\footnotetext{
${ }^{32}$ Cf. Denzer, H., Nachwort, cit. (n. 2), p. 164.

${ }^{33}$ Véase: DenZer, H., Nachwort, cit. (n. 2), pp.161-164.
} 


\section{El Derecho social público.}

Para esa época, Pufendorf era un profesor relativamente desconocido que gozaba solo de un reconocimiento local. Su hermano Esaias, que disfrutaba de un amplio prestigio en la corte de Suecia, procuró para Pufendorf una invitación para dictar lecciones de política en la Universidad de Lund (Suecia). En efecto, en el invierno de 1668-1669 Pufendorf trabajó como profesor de política en la Facultad de Filosofía y como profesor de Derecho natural y Derecho de gentes en la recientemente fundada academia de Lund. Esta academia era una muestra del apogeo que Suecia había alcanzado desde el tiempo de Gustavo Adolfo, gracias a la nueva regulación de sus relaciones políticas y la activa construcción cultural. Un número importante de profesores seguían los vientos reformadores, aunque no muchos. La luterana universidad de Lund acogía el espíritu innovador que dominaba en las academias de profesores y estudiosos de Helmstedt y de Copenhague (Arnisaeus, Calixtus, Conring, Reinking), y que se renovaba con nuevos discípulos, con el propósito de enfrentar al tradicionalismo luterano que profesaban los antiguos profesores en las universidades, incrustados especialmente dentro de las Facultades de Teología y Filosofía. En efecto, Pufendorf fue el alma de esta academia. Por estas razones, la posición de Pufendorf llegó a ser inatacable. Años más tarde publicó un escrito sarcástico y mordaz y de una notable limpieza metódica, en el cual se defiende de los ataques de sus contrincantes. Esta obra apareció en 1686 bajo el título: Eris Scandica, quae adversus libros de jure naturae et gentium objecta diluuntur ${ }^{34}$. El escrito da cuenta del espíritu combativo que existía en el mundo académico, que se reflejaba en la política y en las relaciones internacionales de ese tiempo. Este libro es una mezcla muy bien acabada de controversias científicas ejemplares y registros de sátiras, ironías, sarcasmos y críticas de gran agresividad.

Sin embargo, Pufendorf alcanzó el punto cúlmine de su fama científica con la aparición de su principal obra iusnaturalista, que terminó de redactar y preparar para su publicación en la apacible ciudad de Lund el año 1672, bajo el título: De jure naturae et gentium libri octo ${ }^{35}$; y luego un escrito que se considera ser una breve versión de la obra anterior: De officio hominis et civis juxta legem naturalem, libri duo ("Dos libros acerca de los deberes del hombre y del ciudadano según la ley natural") ${ }^{36}$, editado en Lund, en 1673. Entre el editor y el autor se suscitó una particular relación académica y esto se aprecia en la calidad de la edición. Como es sabido, los autores ejercían una fuerte influencia sobres los impresores de libros y tenían decididamente una directa participación en el resultado de la edición de los escritos. Erasmo de Roterdam y su estrecha colaboración con los editores de sus obras es un buen ejemplo. Erasmo viajaba en Europa de ciudad en ciudad y normalmente residía en casa de los impresores, que eran sus mejores colaboradores. Seguramente, con el fin de corregir minuciosamente las pruebas de las ediciones y también para introducir innovaciones recientes cuando estaba

\footnotetext{
${ }^{34}$ Citado por Denzer, H., Nachwort, cit. (n. 2), p.165.

${ }^{35}$ Publicado en Lund en 1672.

${ }^{36}$ Publicado en Lund en 1673.
} 
sumido en medio de una polémica, ocasión que también presumiblemente aprovechó Pufendorf para la edición de sus escritos.

En el De iure natuae et gentium formula Pufendorf el sistema mayor de su doctrina, que fue estructurada gradualmente a través de sus clases universitarias. De este modo y por primera vez, se presenta en Alemania un sistema cerrado sobre los fundamentos del Derecho natural, donde Pufendorf expone todas las relaciones concretas de Derecho, de individuos provenientes de diferentes estamentos y de diversas comunidades. Así se explica la importancia que tuvo Pufendorf, junto con su amigo Hermann Conring, para la codificación del derecho positivo en Alemania. Sin duda, la influencia de Pufendorf fue significativa para elaboración de los trabajos preliminares del allgemeine Landerecht de Prusia e influyó también en el Bürgerliche Gesetzbuch de Austria y en el proceso de emancipación de las Indias en la América Hispana ${ }^{37}$.

Pufendorf, inicia su obra principal con reflexiones sobre las diferencias de la naturaleza física, la que se origina en las relaciones de causalidad y legitimidad de la materia, la naturaleza moral que conforma los fundamentos para el actuar humano y las relaciones en la vida comunitaria humana, en cuanto en ella se dirimen los valores del libre albedrío y la razón de la naturaleza física. Esto significó la diferenciación de las Ciencias naturales respecto de las morales según sus objetos y la certidumbre del conocimiento científico y el ordenamiento del Derecho natural en la Filosofía moral (Thomasius, Wolff, Kant).

Para el pensamiento jurídico, él consiguió la fijación teórica precisa de la naturaleza humana como fundamento del Derecho natural ${ }^{38}$. La naturaleza humana queda recién completa a través de sus componentes morales de la razón, del libre albedrío y la atadura a una ley. En efecto, este es el motivo de la estructuración de las obligaciones a partir de las relaciones jurídicas y de las pretensiones de Derecho.

Es muy importante dejar en claro que para Pufendorf el Derecho no es el derecho del individuo a todo, sino una consecuencia de la obligación de la vida social. El individuo no es ningún valor absoluto; la naturaleza humana traspasa esto vertical y horizontalmente. Vertical en la sujeción al Derecho y horizontal porque en la vida social concreta hay unos al lado de otros y unos sobre otros. De acuerdo a esta certeza de la naturaleza humana, Pufendorf comprueba el carácter ficticio de la proposición, de muchos autores de ese período, respecto del estado de naturaleza (Hobbes), de la condición natural que no se mide por medio de obligaciones morales provenientes de los anhelos de perfeccionamiento de la naturaleza humana, sino a partir de la condición ordenada de las reglas de las leyes

${ }^{37}$ Para la recepción de Pufendorf en la época de la Ilustración, véase: DefourneAuX, Marcelin, Inquisición y censura de libros en la España del siglo XVIII (Madrid, Taurus, 1973), pp. 44 y siguientes. También Discurso de Juan Martínez de Rozas para la instalación del Congreso, año 1811, citado por EyZAGUIRre, Jaime, Ideario y ruta de la Emancipación chilena (Santiago, Editorial Universitaria, 2002), p. 73.

${ }^{38}$ Véase: Rus Rufino, Salvador, en Pufendorf, Samuel, De los deberes del hombre y del ciudadano según la ley natural (trad. María Asunción Sánchez Manzano y Salvador Rus Rufino, Madrid, 2002), pp. xxvii-xxxiv. 
naturales, así como a la inseguridad de poder seguir la ley, como también por la inestabilidad y las crisis de las relaciones interhumanas. La ley fundamental del Derecho natural, la obligación a la sociabilidad recíproca y la consiguiente obligación absoluta del hombre para que pueda realizarse debido a esto (inviolabilidad del otro, igualdad de todos los hombres ante la ley, ejercicio de la humanidad, fidelidad al contrato), pero esto debe ser leído bajo el supuesto que, para Pufendorf, solo recién es válido cuando existen relaciones contractuales especiales y formas comunitarias humanas en plenitud ${ }^{39}$.

Así, por lo anterior, el derecho natural se presenta como consecuencia de las obligaciones que devienen en los contratos humanos en general, en relaciones contractuales especiales, en la adquisición de propiedad, en el cierre de contratos concernientes a la vida comercial, en las comunidades preestatales tales como el matrimonio, la familia y la comunidad doméstica y, finalmente, en el Estado. Por cuanto, pensamos que Pufendorf cree que recién en el Estado el Derecho natural se convierte en Derecho plenamente válido. Es el Estado, la forma comunitaria humana más completa, que el hombre alcanza su plenitud. Si bien el Estado según su conformación (a través de una creación contractual complicada) es una forma comunitaria humana más bien artificial, según su meta, es al mismo tiempo la forma humana más natural. Es por esto que no es sorprendente que Pufendorf dedicara tanto espacio de su obra al tema de la realización del Derecho natural en el Estado. En efecto, los temas que aborda son muy variados, puesto que trata de la formación y constitución de los Estados, de la soberanía, de las formas estatales, de la limitación y ilimitación del poder, de la injusticia estatal y de la posibilidad del Derecho a la resistencia, de los deberes del gobernante, de las funciones individuales, del poder estatal tal como el de legislar, la defensa, la imposición de penas, la repartición de ministerios y dignidades, la posibilidad de enajenar las propiedades y el estado de emergencia, el derecho de la guerra y la paz, las relaciones externas y finalmente del cambio de los Estados (Pufendorf, Constitución 5, 5-28).

Además, no contento con lo realizado en sus escritos mencionados, Pufendorf reunió para un círculo de lectores más amplio sus ideas sobre Derecho natural y de gentes en un compendio que tituló Von den Pflichten des Menschen und Bürgers nach dem Naturgesetz ("De las obligaciones de los hombres y ciudadanos según la ley natural $)^{40}$. Aquí expone las obligaciones que tienen los hombres hacia Dios, hacia sí mismos, hacia sus prójimos, todas las cuales se conforman a partir de la ley natural, e inclusive dentro del estado natural en las formas comunitarias preestatales, y en las estatales. En la medida que Pufendorf expone su iusnaturalismo como una doctrina de deberes, especifica que el Derecho natural no significa un

\footnotetext{
${ }^{39}$ Véase: Huesbe, Marco Antonio, El iusnaturalismus: Una ideología del Barroco, en Arte y Política del Barroco (Valparaíso, Ediciones Universitarias de Valparaíso, 2000), pp. 35-37; también: H. Denzer, Samuel Pufendorf, Die Verfassung, cit. (n. 2), pp.161-207.

${ }^{40}$ Citado por Denzer, H., Nachwort, cit. (n. 2), p. 168. Salvador Rus Rufino sostiene que la obra Los Deberes provocó un cambio de método en el análisis del derecho natural tan importante que fue acogido por las universidades y en los tratados sucesivos sobre esa materia, De los Deberes, cit. (n. 38), p. xxii.
} 
derecho arbitrario y a priori, y que implica siempre una obligación. Pero el aspecto que en sus escritos se aprecia mayormente es poder determinar que Pufendorf no reconoce ningún derecho natural individual, sino sólo social. De la obra De officio hominis et civis secundum legem naturales aparecieron -contando traducciones y comentarios- más un centenar de ediciones. En ese tiempo, los escritos de $\mathrm{Pu}$ fendorf fueron leídos por los estudiosos tanto como por las personas próximas al poder y a la política (Leibniz, Thomasius, Wolff, Kant).

En 1677 el rey de Suecia, Carlos XI (1660-1697), nombró a Pufendorf historiador de la corte; más tarde lo hizo parte del Consejo secreto y secretario de Estado. En la agitada historia en los países del Norte se sucede una serie de rompimientos de tratados y de guerras entre Dinamarca y Suecia y entre Suecia y Polonia, que terminará por generar profundos cambios políticos que permitirán a la nobleza sueca quedarse con gran parte de las tierras cultivables del país. La efervescencia bélica permanecerá hasta la celebración de la Paz de Utrecht (1714-1715), que dará paso al período donde la diplomacia inglesa iniciará su exitosa política de búsqueda de un "equilibrio europeo", que pone término a la costosa participación de Francia en la política nórdica, polaca y rusa. Rusia reemplaza a Suecia como gran potencia del Báltico. Con estos acontecimientos empieza el período de las obras históricas de Pufendorf. Sin embargo, Pufendorf, a pesar de su importante nombramiento en el reino de Suecia, no participó en los asuntos de gobierno; incluso su memorándum sobre las desventajas de la alianza franco-suecas, que escribió para Suecia en 1680, bajo el título de Dissertatio de occasionibus foederum inter Sueciam et Galliam, es un escrito histórico más bien que diplomático ${ }^{41}$.

$\mathrm{Al}$ escribir historia, él quería mostrar cómo en un Estado concreto, en una situación concreta dada, las tareas que provienen del Derecho natural deben siempre cumplirse de modo que en asuntos de Estado, las tareas adquiridas, han de ser realizadas sea el resultado bueno o malo. Aquí apreciamos una especie de dogmaticismo del principio escolástico, que postula como base fundamental de toda vida civilizada la afirmación, entre otras, de que los pactos han de cumplirse. Esto no significa que se descuide la preocupación por lo concreto y especial del Estado en los problemas de orden universal.

Según el historiador alemán, H. Denzer, Pufendorf se tomó muy en serio escribir historia y sus obras históricas descansan sobre un intenso y cuidadoso estudio archivístico ${ }^{42}$. Pero no se puede esperar objetividad histórica metodológica; para él, los intereses jurídicos con los históricos están ligados inseparablemente. La historia que Pufendorf escribe no es con una genuina intención histórica, sino la de un político en todo el sentido de la palabra. Su preocupación sobre la constitución del Imperio se centra en la pregunta de su tiempo, que quiere saber cómo se debe crear y gobernar un Estado para realizar correctamente la tarea de una comunidad política y cómo, sobre todo, en el quehacer práctico, el gobernante de su época encuentra la realidad objetiva en las condiciones dadas de su misma situación histórica. En efecto, Pufendorf percibe en el carácter de los alemanes

\footnotetext{
${ }^{41}$ Citado por Denzer, H., Nachwort, cit. (n. 2), p.168.

${ }^{42}$ H. Denzer, H., Nachwort, cit. (n. 2), p.168.
} 
y en las obligaciones políticas, la verdadera realización de los fines duraderos del Estado. Es por esto que Pufendorf no llega a ningún juicio que pretenda abarcar toda la historia europea de su tiempo. Su escribir histórico se queda encerrado en el punto de vista del Estado en que se encuentra. Esto se ve especialmente claro en la "Introducción a la historia de los reinos y estados más importantes que se encuentran en este tiempo tan complicado" hechas a partir de sus cátedras dictadas en Lund y en Francfort del Main ${ }^{43}$.

Para su tarea de historiador de la corte sueca, Pufendorf compiló dos obras: una historia del reino sueco desde la expedición de Gustavo Adolfo en Alemania (Commentariorum de rebus Sueciis libri 26 ab expeditione Gustavi Adolphi in Germaniam ad abdicationem usque Christinae $)^{44}$; y la historia del tiempo del reinado de Carlos Gustavo (De rebus a Carolo Gustavo Sueciae regis gestis commentariorum libri 7 postumo $)^{45}$. Desde 1684 el príncipe elector trató de ganarse a Pufendorf como historiador de la corte de Brandemburgo, esto es, al servicio del gran ducado de Prusia. Sin embargo, sólo cuando se hizo pública la derogación del Edicto de Nantes de 1685 por Luis XIV, Pufendorf recién pudo aparecer al servicio del líder de los protestantes en Alemania y manifestar su malestar en contra de aquel acto de intolerancia religiosa ${ }^{46}$. Después de largas negociaciones con el rey de Suecia, el Gran Príncipe Elector, poco antes de su muerte, consiguió finalmente que Pufendorf se trasladara a Berlín (1688). Estando al servicio del príncipe elector, Pufendorf escribió una historia del tiempo de su reinado (De rebus Friderici Wilhelmi Magni Electoris Brandenburgici commentariorum libri 19) completado en 1692 y publicado en Berlín en $1695^{47}$.

Por último, cabe mencionar el informe para la unidad de los protestantes: Jus feciale Divinum sive de consenso protestantium ${ }^{48}$. Su meta era delimitar la autonomía de la sociedad al ámbito de la decisión política. El 26 de octubre Pufendorf murió después de una larga enfermedad, legando un extenso testimonio secular y testimoniar con su vida y escritos un siglo de experiencias (1632-1694).

\section{CONCLUSIÓN}

Después de haber conocido los textos constitucionales de la Ley Regia danesa, la Constitución del Imperio alemán y los hechos ocurridos en el mundo político poswestfaliano, no cabe duda que el gran innovador y responsable de los cambios que se introdujeron al sistema político del siglo XVII es S. Pufendorf. Él es quien logra definir un nuevo gran marco conceptual para el manejo del Estado, fundamentalmente a partir de su particular consideración del Derecho Natural

\footnotetext{
${ }^{43}$ Véase: PuFENDORF, Samuel, Einladung zu der Historie der voenehmsten Reiche und Staaten so itziger Zeit in Europa sich befinden (1682).

${ }^{44}$ Utrecht, 1686.

${ }^{45}$ Nürnberg, 1696.

${ }^{46}$ En 1687 publicó su teoría sobre las relaciones del Estado con la Iglesia en respuesta a la revocación del edicto de Nantes en 1685 bajo el título de De habitu religionis christianae ad vitam civilem.

${ }^{47}$ Berlin, 1695.

${ }^{48}$ Lübeck, 1697.
} 
y del Estado. Todo esto, gracias a su privilegiada oportunidad de apreciar los acontecimientos desde una posición académica tanto como política. Por último, podemos agregar que con Pufendorf se inicia definitivamente la discusión intelectual sobre el Derecho público alemán, en toda su extensión. Esto sucede de esta forma al poner Pufendorf sobre la mesa su texto constitucional para ser sometido al debate, por lo cual, aún hasta nuestros días, se considera a Pufendorf una pieza fundamental para construir una parte de un proyecto, con el fin de elaborar una constitución común para la actual Unión Europea.

[Recibido el 25 de mayo y aceptado el 10 de julio de 2009].

\section{BIBLIOGRAFÍA}

Allen, John William, A History of Political Thought in the Sixteenth Century (London, Methuen, 1960).

Althusius, Johannes, Politica methodice digesta (Herborn, 1603).

ARnisaeus, Henning, De republica (1615).

Arnisaeus, Henning, De jure majestatis (1610).

Arnisaeus, Henning, Opera Omnia (1630 y 1648).

Darnton, Robert, El negocio de la Ilustración. Historia editorial de la Encyclopédie, 1775-1800 (trad. F. C. E., México, 2006).

Defourneaux, Marcelin, Inquisición y censura de libros en la España del siglo XVIII (Madrid, Taurus, 1973).

Dilthey, Wilhelm, Hombre y mundo en los siglos XVI y XVII (trad. cast., México, 1947).

DöRING, Detlef, Pufendorf-Studien: Beiträge zur Biographie Samuel Pufendorf und seine Entwicklung als historischer und theologisher Schriftsteller (Berlin, Dunker und Humblot, 1992).

Dorschner, Johann, Erhard Weigel und seine Zeit, en SCHIELICKE, Reinhard y otros (editores), Erhard Weigel 1625 bis 1699. Barocker Ersvater der deutschen Früaufklärung. Beiträge des Kolloquiums anlässlich seines 300. Todestages am 20. 1999 in Jena (Jena, 1999).

Eyzaguirre, Jaime, Ideario y ruta de la Emancipación chilena (Santiago, Editorial Universitaria, 2002).

Gelderen, Martin van, The State and its Rivals in Early-Modern Europe, en SKInNER, Q. (editor), State and Citizens: History, Theory, Prospects (Cambridge, 2003).

Grotius, Hugo, The Right of War and Peace (traducción de Richard Tuck, Indianapolis, Liberty Fund, 2005).

HobBes, Thomas, Leviathan or the Matter, Form and Power of a Commonwealth Eclesiastical and Civil, (Amsterdam, 1668).

Huesbe, Marco Antonio - Carvajal, Martín Lutero y Juan Calvino. Fundamentos del Mundo Moderno (Valparaíso, Ediciones Universitarias de Valparaíso, 2003).

Huesbe, Marco Antonio, Die konstitutionelle Auseinandersetzung "Absolutismus vs. Liberalismus" in der deutschen Politikwissenschaft des 17. Jahrhunderts: Johannes Althusius vs. Henning Arnisaeus, en Jurisprudenz, Politisce Theorie und Politische Theologie. Beiträge des Herborner Symposions zum 400. Jahrestag der Politica des Johannes Althusius 1603-2003 (Berlin, Duncker u. Humblot, 2004). 
Huesbe, Marco Antonio, Die Rezeption des Staatslehre des Henning Arnisaeus in Europa und Dänemak, en Goll, Th. y otros (editores), Staat und Politik. Beiträge aus Politischer Wissenschaft und Politischer Bildung. Festschrift für Paul-Ludwig Weinacht zum 65. Geburtstag (Baden- Baden, Nomos, 2003).

Huesbe, Marco Antonio, El iusnaturalismus: Una ideología del Barroco, en Arte y Política del Barroco (Valparaíso, Ediciones Universitarias de Valparaíso, 2000).

Huesbe, Marco Antonio, La Constitución de Pufendorf, en Homenaje al Profesor P. L. Weinacht (Santiago 2009).

Huesbe, Marco Antonio, Teoría, Administración y participación en el Estado moderno. Bodino, Arnisaeus, Beza (Valparaíso, Ediciones Universitarias de Valparaíso, 2008).

Huesbe, Marco Antonio, Una constitución de la época del absolutismo: la "Lex regia Danica” de 1665, en Revista de Estudios Histórico-Jurídicos 1 (Valparaíso 1976).

Huesbe, Marco Antonio, Untersuchungen, zum Einfluss der Schule von Salamanca auf das luttherische Staatsdenken im 17 Jahrhundert (Diss. Mainz, 1965),

Lex Regia de jure supremae potestatis et haereditariae successionis Regni Danae, en Lex regia Frederici Tertii ad mandatum Sae. Regiae majestatis prorium (Kopenhavn, 1655).

MonZambano, Severinus von, Über die Verfassung des deutschen Reiches (traducción e introducción por Harry Bresslau, Berlín, 1922).

Pufendorf, Samuel, Commentariorum de rebus Sueciis libri 26 ab expeditione Gustavi Adolphi in Germaniam ad abdicationem usque Christinae (Utrecht, 1686).

PUFENDORF, Samuel, De habitu religionis christianae ad vitam civilem (1687).

PufENDORF, Samuel, De los deberes del hombre y del ciudadano según la ley natural (trad. María Asunción Sánchez Manzano y Salvador Rus Rufino, Madrid, 2002).

PufEndorf, Samuel, De rebus a Carolo Gustavo Sueciae regis gestis commentariorum libri 7 postumo (Nürnberg, 1696).

PufEndorf, Samuel, De rebus Friderici Wilhelmi Magni Electoris Brandenburgici commentariorum libri 19 (Berlin, 1695).

Pufendorf, Samuel, Die Verfassung des deutschen Reiches (traducción de Horst Denzer, Stuttgart, Philipp Reclam Jun, 1985).

PufENDORF, Samuel, Einladung zu der Historie der voenehmsten Reiche und Staaten so itziger Zeit in Europa sich befinden (1682).

Pufendorf, Samuel, Jus feciale divinum sive de consenso protestantium (Lübeck, 1697).

Pufendorf, Samuel, La Constitución del Imperio alemán. 1667 (Valparaíso, Edeval, 2009).

PufFendof, Samuel, De jure naturae et gentium libri octo (Lund, 1672).

Puffendof, Samuel, De officio hominis et civis juxta legem naturalem, libri duo (Lund, 1673).

PufEndorf, Samuel, Monzambano, eines veronesers ungeheurter offenherziger Discurs, oder Gründlicher Bericht von der wahren Beschafenheit und Zustand des Teuschen Reichs, geschrieben an seinen Bruder Laelium von Monzambano. Herren zu Trezoland [...] ins teutsche übersezet durch ein ungenantes Glied der hochlöblichen Fruchtbringeden Gessellschaft. 1669 [reimpreso en Staatslehre der frühen Neuezeit (Frankfurt am Main, Deutscher Klassiker Verlag, 1995)].

SEIDler, Michael, The Works of Samuel Pufendorf, escrito introductorio a PUFENdorf, Samuel, The Present State of Germany (traducción de Edmund Bohun, Indianapolis, Liberty Fund, 2007).

Monzambano Veronensis, Severinus de [= Pufendorf, Samuel], De statu imperii 
Germanici ad Laelium fratrem, dominum Trezolani, liber unus (Genevae, apud Petrum Columesium, 1667).

STOLLEIS, Michael, Geschichte des öffetlichen Recht (München, 1988).

STONE, Lawrence, La revolución inglesa, en ElLIOT, J. H. y otros (editores), Revoluciones y rebeliones de la Europa Moderna (Madrid, Alianza Editorial, 1986).

Sutherland, Arthur, De la Carta Magna a la Constitución Norteamericana. Ideas fundamentales sobre Constitucionalismo (Buenos Aires, TEA, 1972).

WilloweIT, Dietmar, Hermann Conring, en STOLLeIs, Michael (editor), Staatsdenker im 17. Jahrhundert. Reichspublizistik, Politik, Naturrecht (Frankfurt am Main, Metzner, 1987). 
